\title{
Reconciliation as Relationship: Exploring Indigenous Cultures and Perspectives Through Stories
}

\author{
Natsuko Motegi
}

\begin{abstract}
Natsuko Motegi has been working as an early childhood educator since 2002 after obtaining her MEd in curriculum and instruction from the University of British Columbia. She builds preschool curriculum based on children's interests and inquiries and strongly believes in the importance of documentation as a tool to observe, record, and reflect on the process of curriculum building as well as to make the children's learning visible. She has been working at Marpole Preschool since 2005 and also teaches a responsive curriculum course in the early childhood education program of Burnaby School District's Community and Continuing Education. Email: natsukomo@gmail.com
\end{abstract}

Responding to the calls to action of the Truth and Reconciliation Commission of Canada, a non-Indigenous author and her coeducator embarked on a learning and research journey with 4-year-old children in a preschool program. The challenge for the educators was to make the experience meaningful to the children rather than handing down a set of information on Indigenous cultures and history. Through exploring Indigenous stories, both the educators and the children shared their wonderings and coconstructed the meanings of them. Developing authentic appreciation toward Indigenous cultures and values through the power of stories became a first step toward reconciliation.

Key words: Truth and Reconciliation; Indigenous cultures; pedagogical documentation; teacher research

How can we incorporate Indigenous cultures and perspectives into our preschool program? How can we make it meaningful and age appropriate for the children? What is our part in the process of reconciliation? These are questions Gabi Kirton and I, as the educators at Marpole Oakridge Community Centre Preschool, have asked ourselves. We feel strongly that we are called to take an action for Truth and Reconciliation "to come to terms with events of the past in a manner that overcomes conflict and establishes a respectful and healthy relationship ... between Aboriginal and non-Aboriginal peoples in this country" (Truth and Reconciliation Commission of Canada, 2015a, p. 6), and we also acknowledge that we live, work, and play on the unceded traditional ancestral territories of the ${ }^{\mathrm{w}} \mathrm{m} ə \theta \mathrm{k}^{\mathrm{w}}$ əy่วm (Musqueam), skwwxwú7mesh (Squamish), and selílwitulh (Tsleil-Waututh) First Nations. While we wanted to bring Indigenous perspectives into the program, we have been hesitant, mainly because of possible misrepresentation of Indigenous cultures, history, and values. Being nonIndigenous and rarely having Indigenous families in our program, we have been unsure how to start respectfully engaging with Indigenous culture. We pondered different ways to incorporate an Indigenous perspective in our curriculum and came to agree that exploring an Indigenous story through children's questions and thoughts might lead us on our journey of Truth and Reconciliation in early childhood education.

\section{Background}

Marpole Preschool has provided responsive curriculum inspired by the preschools of Reggio Emilia, Italy, for the last two decades. The educators have been studying various works from Reggio Emilia and others inspired by this approach (Avery, Callaghan, \& Wien, 2016, Cadwell, 1997; Curtis \& Carter, 2017; Edwards, Gandini, \& Forman, 2012; Fraser, 2012; Pelo, 2007) and have adopted and modified ideas to suit their own practice. Currently the curriculum cycle at Marpole Preschool flows from (1) observing children's experiences, (2) reflecting and sharing multiple perspectives among staff, children, their families, and other professionals, (3) offering experiences to the 
children responding to their wonderings and interests, and back to (1) observation to continue the cycle. This process is often documented for further discussion as the curriculum cycle goes on. The documentation panels are displayed to make the children's learning visible to the families and also to revisit the experiences with children to deepen their understanding and define their inquiries. The current staff share an image of the child who is curious, competent, collaborative, and a critical thinker. The preschool environment provides a space for children to work both socially and individually according to their interests and intentions. The educators strive to provide "one hundred languages" (Malaguzzi, 2012) for children with different materials and methods to investigate their wonderings and communicate their ideas.

\section{Exploration of an Indigenous story}

The opportunity arose when the children in the four-year-old group showed interest in birds by making birds in the art area, singing a bird song, and acting out a bird story. Hoping to explore an Indigenous story as an entry point to respectfully engage with Indigenous perspectives, we started to search for a story of a bird that could capture the children's interest. Soon we came across the commonly told Indigenous story How Raven Stole the Sun from different sources. In the story, Raven the trickster looked for light for people who lived in darkness and successfully withdrew the sun from the box in Sky Chief's house using his trickery and the power of shape-shifting. A raven is a common figure among many North American Indigenous stories and is often the trickster. This particular story of the raven bringing the sun is prevalent, with some variations through many Indigenous communities in the northwest region of Canada, such as Tlingit, Haida, and Kwakwaka'wakw (Westcoast Child Care Resource Centre, n.d.). We wondered: Could this story lead us to authentic understanding and appreciation of Indigenous cultures? Would the children develop their curiosity respectfully toward Indigenous cultures? Would we, the educators, misinterpret the story and therefore misrepresent Indigenous perspectives? Though we felt uneasy in presenting a story that was unfamiliar to us, we eventually decided to tell it after finding many websites and resources that led us to the same story. During my research I collected felt board pieces, the book Raven: A Trickster Tale from the Pacific Northwest (McDermott, 2001), and a story kit with the characters painted on small rocks and other related props in a replica of an Indigenous bentwood box from Westcoast Child Care Resource Centre. We told the story using the felt board pieces first, reasoning that the book had more details and was very complex for the children to take in all at once.

The exploration of How Raven Stole the Sun started slowly, and the children received it with sincere curiosity. It provoked some questions:

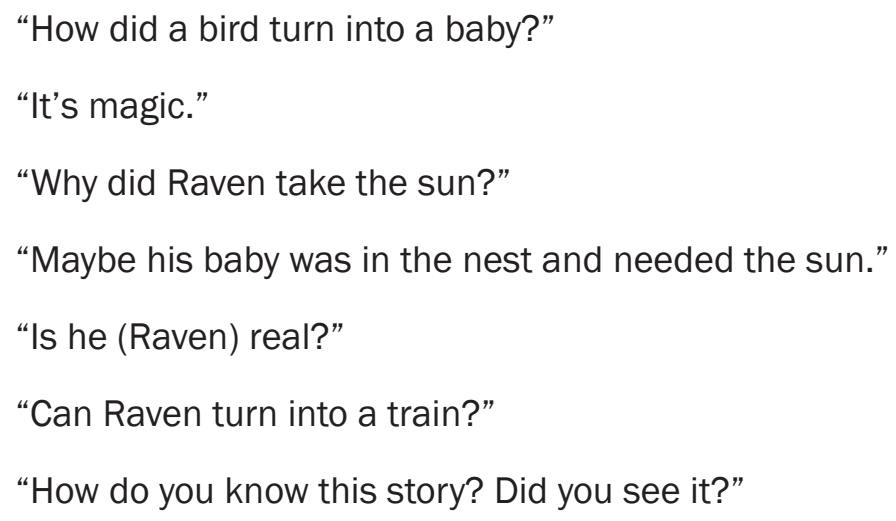

I was also filled with my own questions after listening to the children's questions. Is it appropriate to interpret the Indigenous story in many ways? Stories usually give listeners a chance to interpret and understand through 
personal views, but is it acceptable to do so with an Indigenous story? Is there a certain way to interpret and understand the story? How do Indigenous people tell this story to their children? What values do they want them to take from it? Are there any characters that Indigenous people relate themselves to in this story, such as people without light, Raven the trickster, Sky Chief, or his daughter?

Regardless of our uncertainty, we told the same story for a few days. When we finished storytelling each time, the children would often start discussion with enthusiasm.

"Raven is so nice (to bring light to people)."

"It's nice of Raven."

"No, it's not nice to take the sun."

“If he doesn't take the sun, people don't have the sun. They have to use the light on the car."

“They don't have the flashlight. It's a long time ago. There were horses.”

"The chief took the sun. He was a bad chief."

The children seemed to ponder morality in the story: "Why was the chief keeping the sun to himself? How did he get it?" "Why did Raven take the sun? It is not nice." "But Raven helped people and made them happy." Was it these moral issues that engaged the children deeply in the story? Were they curious because they were developing a sense of justice, wanting to know what is right and what is wrong?

Over time, however, the children developed a shared understanding that people were in darkness and Raven felt sad for them. They eventually gained a perspective to see Raven as helpful and kind. After the storytelling session one day, the discussion led to another wondering:

"Raven took the sun so everyone has light. He saved the day. He helped people."

"Why did Raven take the sun? Sun is very hot."

"But he is very strong."

"Raven is not good at holding the sun. The sun is really, really hot!"

Responding to this discussion, we decided to tell another version of the same story, in which Raven was originally thought to be white, but in the process of bringing out the sun, it turned black (Kients, 2012; Raven Tales Productions, 2005; Williams, 2001). We shared with the children that the same story could be told in different ways in different Indigenous cultures. When the story was finished, the children exclaimed with a sense of comprehension:

“Raven got burned!"

"The sun was too hot."

"I was sure about the sun was very hot. Raven cannot touch it."

“He burned his mouth."

“He got hot and ouchy."

Through the exploration of the Raven story, we rediscovered a strong image of a child who is capable and reflective. Previously I wondered through which character in the story Indigenous people would see themselves and how 
they would interpret the story. Contrary to my expectation and desire to "get it right," the children's discussion showed multiple understandings of the story. The exchange of different views was genuine, and the children listened to each other carefully and shared their ideas seriously, allowing themselves to see diverse and complex interpretations of the story. One child's painting demonstrated another possible interpretation. She saw the story through Sky Chief's daughter's eyes and made meaning of it. She explained, "She is sad because the baby was gone and the raven was away." Her deep understanding of attachment between a child and his mother astonished us.

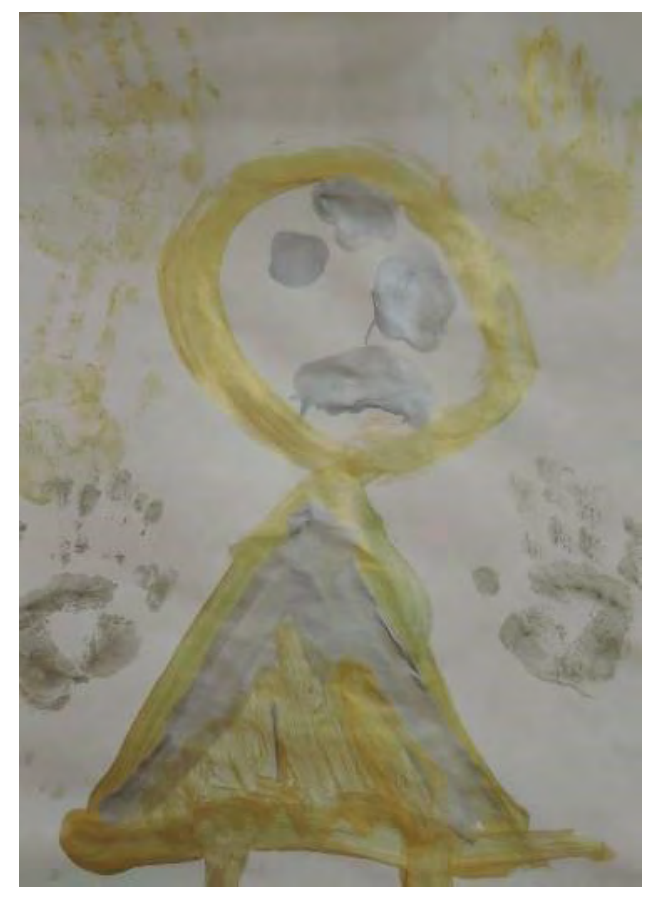

Figure 1. Sky Chief's daughter. "She is sad because the baby was gone and the raven was away."

Exploring the story How Raven Stole the Sun with the children continued for three weeks using different props and materials: the replica of a traditional bentwood box from west coast Indigenous communities such as Haida; rocks painted with the characters of the story borrowed from Westcoast Child Care Resource Centre (n.d.); and the book (McDermott, 2001). I noticed myself feeling more comfortable with interpreting an Indigenous story. I felt reassured by Harvey McCue and Associates (2010), who state:

Non-Aboriginal people often recorded First Nations legends as fairy tales or myths, adding convenient morals to sum up the story. However, the stories of Elders and accomplished storytellers often have no such ready explanation. The listener was expected to take time to think about the story and its meanings. (para. 18)

Harvey McCue and Associates (2010) emphasize repetition as an important element of Indigenous storytelling in order for the stories "to be told and 'felt' over and over again" (para. 20). Jo-Ann Archibald (2008) agrees, stating, "One does not have to give a meaning right after hearing a story, as with the question-and-answer pedagogical approach. An important consideration is hearing stories over time so that they become embedded in memory" (p. 25). I recognized the same value in our storytelling, which was repeated for many days so that the children would take in the story's meanings slowly. The repetition also allowed them to ponder their own questions and share their understandings. Our learning process also coincides with one of the First Peoples Principles of Learning (First Nations Education Steering Committee, 2008) that says, "Learning is holistic, reflexive, reflective, experiential, and 
relational." The children and educators at Marpole Preschool experienced the power of storytelling by engaging with an Indigenous story and exploring it deeply through telling and retelling it, as well as sharing reflections and wonderings.

\section{Exploring the story with "the hundred languages"}

The founder of the Reggio Emilia schools, Loris Malaguzzi, inspires us in his poem, saying, "The child has a hundred languages, a hundred hands, a hundred thoughts, a hundred ways of thinking, of playing, of speaking" (2012, p. 3). In our program, we make a conscious choice to offer opportunities for children to express their ideas in different ways other than verbal communication, such as designing, painting, drawing, or building, because we believe each child has a different approach to learning, as well as different talents to communicate their thoughts. Since the children were keen to continue the Raven story exploration, we invited them to act it out as another language of expression. They were thrilled and called it "a show." Some children quietly acted, while others spontaneously created their own lines, such as "I am going to search for light."

Through acting, the children explored their earlier questions, such as, "How did the chief get the sun in the box?" They brainstormed:

"He just took it."

"He grabbed it and put it in the box."

"Raven took the sun for the chief."

As the children continued to act and tell the story through different roles, the chief's part evolved from "He just grabs the sun!" to "He needs to get on the ladder because the sun is too high."

The emotions of the characters also became expressive through acting since the children gave more thought to how they should act. They said the chief needed to look "angry" because he would say, "I keep it (the sun) all to myself" and "not share." When the Raven Child was crying for the sun, the children acting as the Chief and his daughter showed love and care to console him.

While their acting developed, the effects of room lights and the use of props (e.g., the Raven took off the black fabric used as wings when it turned into a baby) evolved over four weeks. Boys and girls took turns over time to play the Raven, Sky Chief, and the daughter, regardless of their gender. They formed relationships with the characters, especially Raven, because they were represented in their dramatic play during playtime and through many artworks.

Another "language" (Malaguzzi, 2012) we provided for the children was drawing to explore their ideas rather than verbal discussion. As they drew, they exchanged their thoughts:

"The raven is good."

"People feel good (with the sun)."

"I like Raven."

"He saved the day."

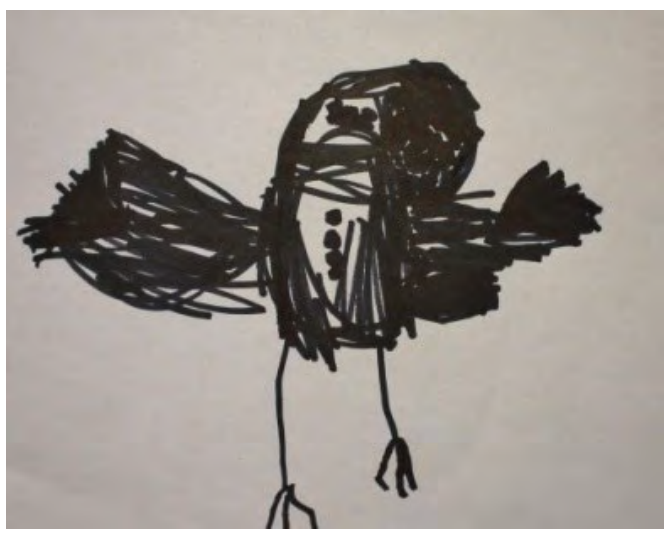

It seemed most of the children shared the view that Raven was good

Figure 2. Raven with buttons. 
to bring the light to people. Some children drew all the main characters: Raven, Sky Chief and his daughter. We also noticed some children took time to depict each scene as they drew. The process of drawing itself became an opportunity to tell the story, and some of the drawings started to represent the sequence of the events.

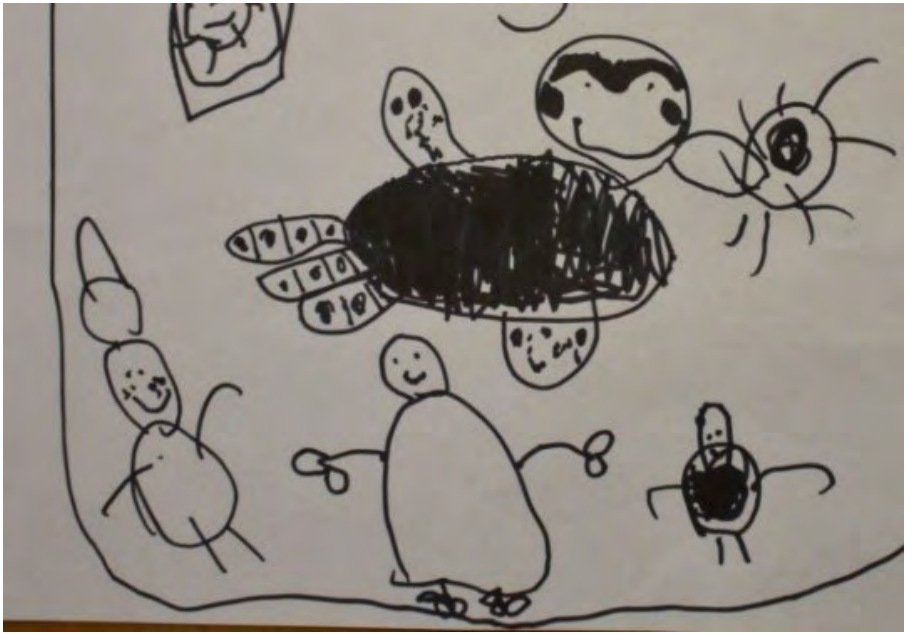

Figure 3. The bentwood box with the sun inside. Raven with the sun in his beak. Chief, his daughter, and the raven child.

After drawing for a few days, there was a great collection of drawings. As we organized them in order, we noticed there was almost a complete set of illustrations that represented the entire story. The children were excited to see it, and they drew more pictures for the missing scenes. The collection of drawings grew, and finally there were enough pictures to tell the whole story of How Raven Brought the Sun. We bound the pictures to make a book and read it to the children as "illustrated by the children of Marpole Preschool." A sense of pride was shared in the class, and at the end of the day, one child brought her mother to show the book "illustrated by us."

Raven the trickster puppet designed by Doug LaFortune,

a Coast Salish artist, also added another dimension to the children's relationship building with the character and provided different "languages" in their play. When I introduced it to them, the children started to talk to it.

"Hi, my name is Fatima. I have a baby brother."

"You should break the door at the chief's house. Then you didn't get dirty" (by going through the smoke hole as in the version by Williams [2001]).

"Can I play with you, Raven?"

We told two other stories of Raven the trickster using the puppet; one was adopted from Heroes and Heroines in Tlingit-Haida Legend (Beck, 1989) about how Raven got fresh water and spread it to create rivers, and another was Raven Goes Berrypicking (1991) by Ann Cameron. Every time a story was finished, the children asked with excitement, "Do you have any more Raven stories?" Both of these stories were explored deeply over time with different materials. The children enjoyed playing with the puppet and telling the stories they learned. The puppet soon became like another classmate, and the children expressed genuine affection toward Raven. On Valentine's Day, some children made a card for the puppet and said, "I love you, Raven!"

\section{Turning point and self-critiquing}

After exploring the Raven stories for three months, I visited Westcoast Child Care Resource Centre. Looking for new materials and inspiration, I picked up a drum in the library and wondered "Could we explore drumming as 'the heartbeat of Mother Earth"' (Bear \& Huff, 2016, p. 5; Meuse-Dallien, 2003, p. 51)? A man shared with me that he was a drummer from Musqueam, the local Indigenous community, and sang for a living, and was currently taking early childhood education courses. On the spot I excitedly shared what we had explored at the preschool. He acknowledged that we had learned a lot about Haida culture, one of the Northwest Coast Indigenous communities, but he also challenged me by asking, "What about Musqueam?" Even the Raven story that we thought was a prevalent Indigenous story, he pointed out, was from Haida. He thanked me for our effort to bring Indigenous 
cultures to the non-Indigenous children at preschool, and encouraged me to look into local Indigenous cultures.

This encounter made me reflect carefully on our past learning journey of Indigenous cultures at preschool, and I realized I had wrapped and presented to the children "Indigenous people" as one big entity without being aware. Though I knew there were different cultures, nations, and experiences among Indigenous peoples, I called them conveniently "Indigenous people" under one big umbrella and failed to acknowledge their diversity. Then, what approach would have been better and more meaningful to the children? I was initially motivated to incorporate Indigenous worldviews in our program because we share this land with Indigenous peoples. If so, we need to look more into the local Indigenous cultures, stories, and worldviews that are imbedded in this land. It would make more sense for the children who live on this land to learn the traditions and values that emerge here.

As early childhood educators, we are trained to avoid misrepresentation and stereotyping of a certain culture when we introduce it to children. To avoid any bias or stereotype, Julie Bisson and Louise Derman-Sparks (2016) suggest that educators reflect critically to uncover their own beliefs and feelings about specific cultures, to identify the messages of the activities they provide, and to consider concerns and perspectives of the families and the staff. I realized that introducing How Raven Brought the Sun to the children as "Indigenous" would create the perception that all Indigenous peoples share the same story. Cheryl Bear and Tim Huff (2016) point out that "it is often assumed that all Indigenous People in Canada and the USA have totem poles and live or lived in tipis. But this is a stereotype" (p. 15). Though I had been careful not to misrepresent the Indigenous story, I misled the children without knowing. Maggie MacNevin and Rachel Berman (2017) point out that "children are actively constructing their own understanding of race" (p. 835). I could see my class of children making meaning of who "Indigenous" people are through the story. The authors suggest that "educators engage in a continuous cycle of self-reflection and focused, thoughtful observation of children's play and social interactions" (p. 837), and my conversation with the ECE student from Musqueam Nation made me aware that I had not been careful enough and had presented an overgeneralized view of diverse Indigenous cultures in Canada.

\section{Engaging with a story from the Musqueam Nation}

I started to search for a story from the Musqueam Nation to bring children's focus to the local Indigenous people to help them develop deeper understanding of Indigenous perspectives rooted where they lived. Though I found a few Coast Salish stories, they were not specifically from Musqueam. I visited Westcoast Child Care Resource Library and public libraries in different municipalities, where I was told it would be difficult to find a story that was from a specific Indigenous nation. I went to Xwi7xwa Indigenous Library at the University of British Columbia (UBC), and they had only one children's book from Musqueam, Let's Take a Walk (Grant, 2013), in which the author describes his childhood with a Chinese father and a Musqueam mother. The book was in the special collections and was not available for loan. The librarian searched for the source of the book and found that the Musqueam Cultural Centre Gallery might have a copy. At the gallery, I found other books, but they were written in the hən'q́əmin'əm' language. The receptionist tried to find someone who could answer my question of where to find a Musqueam story, and gave me a name and contact number. I contacted the person and shared my learning journey and struggle to find a Musqueam story that I could share with the children. She could not think of a story right away and asked me for some time. The research was a struggle, and I was learning to accept that "there are certain things that are not for public consumption. They're for our (Musqueam's) cultural benefit, for our identity, and for our own community's self-worth" (Grant, as cited in Pape \& Dodds, n.d.). I continued my research, however, feeling it was important for us to know more about Musqueam people and culture considering that Marpole Preschool was located in the area of the Musqueam village called cəsna?əm dating back at least 4,000 years. 
The answer came from another source. The ECE student from the Musqueam Nation that I had met at Westcoast Library connected me with his uncle, a Musqueam Elder. He was concerned about my process of Indigenous exploration at the preschool and possible lack of knowledge about Indigenous cultures, particularly Musqueam. We had a meeting right away and shared our experiences and viewpoints. Upon my request of learning a Musqueam story, the Elder shared two stories with me and the titles of two books as resources. One of the stories was found in Musqueam Reference Grammar (Suttles, 2004) as a sample of language use, hən'q́əmin'əm', the Downriver dialect of the Salishan language Halkomelem. Musqueam means "people of grass" and the story tells how they came to be called so.

\section{The Musqueam story of the double-headed serpent}

In order to connect the origin of the story and where we live, we invited the children to explore maps for a few weeks. While we explored the map of Canada, they shared their knowledge of maps in general:

"I live in Canada so I live right here."

"I think school is around here."

"My house has a number."

"I live in Canada and I have the number, too."

"My number has to be 749."

"If you are lost, you need a map."

"My car has a map that talks and tells you a way."

The conversation showed us that the children understood that a map represents a place, and they could use it as a tool to locate themselves and navigate to another place. Responding to their understanding of a map, we explored further with a Vancouver road map that included street numbers. We looked together at the locations of the preschool and the children's homes, and the children recognized some street names and parks on the map. Using this map, I decided to tell the Musqueam story, hoping that it would help them connect the story with the place. I pointed at the spot on the map which used to be the lake where the double-headed serpent lived. I told the story that the massive serpent with two heads went through the Musqueam people's village and made a river. From the

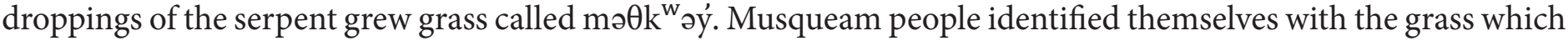
grew back strong even after it withered, and they became known as Musqueam, the people of mə$\theta \mathrm{k}^{\mathrm{w}}$ əy' (grass).

The children's initial reaction to the story was curiosity and a slight fear of the large two-headed snake. They discussed:

"Is this real?"
"I think it is a story."

We repeated the story for a few days, and wonderings and fear around the double-headed serpent continued to emerge in the children's play. Some of them, for example, pretended, "The serpent snake is coming. The one with two heads. Everyone, hide!" Through repeated telling of the same story, the children slowly became storytellers and shared their thoughts.

"It's the serpent snake." 
"Two-headed snake."

"That makes me have a bad dream."

“Grass grows up, and they said, 'It's alive!'”

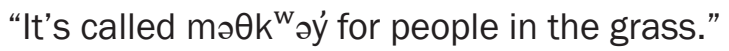

"People eat the grass and next time people eat again."

"It keeps you healthy."

We shared the two-headed serpent images created by Musqueam artists Susan Point (Croes, Point, \& Wyatt, 2014, p. 62) and Brent Sparrow, Jr. The children were particularly impressed with Sparrow's Double-Headed Serpent Post that was raised in 2016 at UBC, and exclaimed, "Wow! Very cool!" Being curious about their impression of the double-headed serpent, we invited the children to draw what they thought it looked like.

While some children drew the image of Sparrow's Double-Headed Serpent Post, others drew a "double-headed serpent and a Musqueam person" or the house in which the Musqueam people hid.

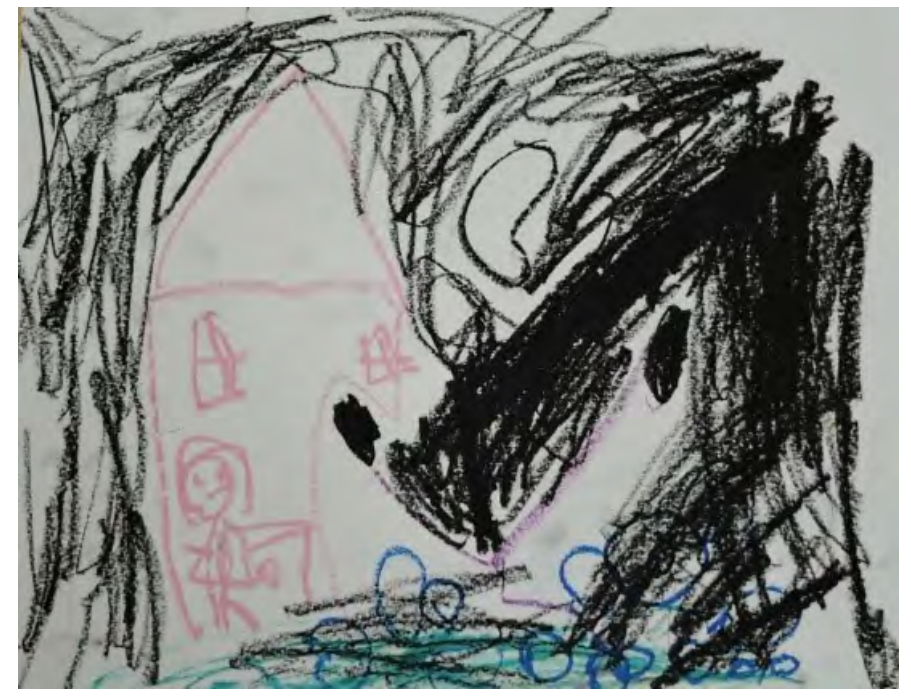

Figure 4. "Double-headed serpent came at night."

The children often included "poo" and "grass" in their drawings as important parts of the story. As we often do, we allowed children to continue exploring their ideas through drawing for a few days, and some children's drawings grew from the simple depiction of the story to their own versions of the story.

“Double-headed serpent is mad. He's going to the ocean. He's going to get food. He will get food for everyone."

“The snake came at night and bonked on the grass, 'Ow!”

“Double-headed serpent said, 'Sorry for ruining the fun.' They bonked their head and people put bandages on them. Double-headed serpent was trying to get pears because they were hungry."

The pictures of the double-headed serpent getting "bonked" or eating fruits made us wonder if they were making the scary serpent more humorous and approachable. 
There was also a story of the double-headed serpent getting attacked by a superhero.

"It's Anpan Man and crocodile fighting the snake. Crocodile bite and bite. The two-headed snake said, 'Ouch! Ouch!'”

When they retold the story using the props, locking up the door for safety and attacking the serpent were prominent.

"People locked up their doors."

"They said, "Lock up your house! Two-headed snake is coming!"

"I'm gonna cut the head off."

It seems that locking up or fighting back was their way to feel secure and more powerful than the serpent.

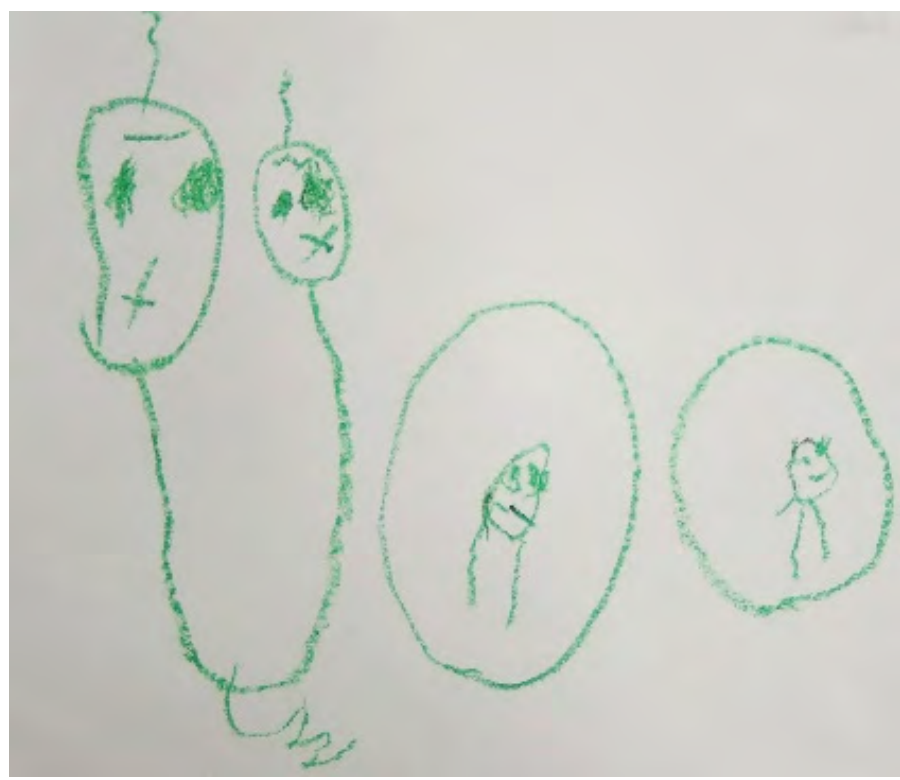

Figure 5. "Double-headed serpent said, 'Sorry for ruining the fun.' They bonked their head and people put bandages on them."

While we frequently revisited the story as a group during circle time, some children made the double-headed serpent out of paper during playtime. They drew two snake heads and attached them with a piece of tape which also represented a tail. They used the self-crafted serpents as puppets and acted out.

"Double-headed serpent is eating the flowers! Yum, yum, yum..."

“Now it’s eating ice cream!"

After feeding the puppet serpents well at the play kitchen, they moved on to the couch and announced, "Doubleheaded serpent is sleepy now," and pretended to sleep. Though the children perceived the double-headed serpent as scary at the start of the exploration, it seems that they found a way to make it less scary through drawing, storytelling, and pretend play. The serpent players made more double-headed serpents over a few days, and we

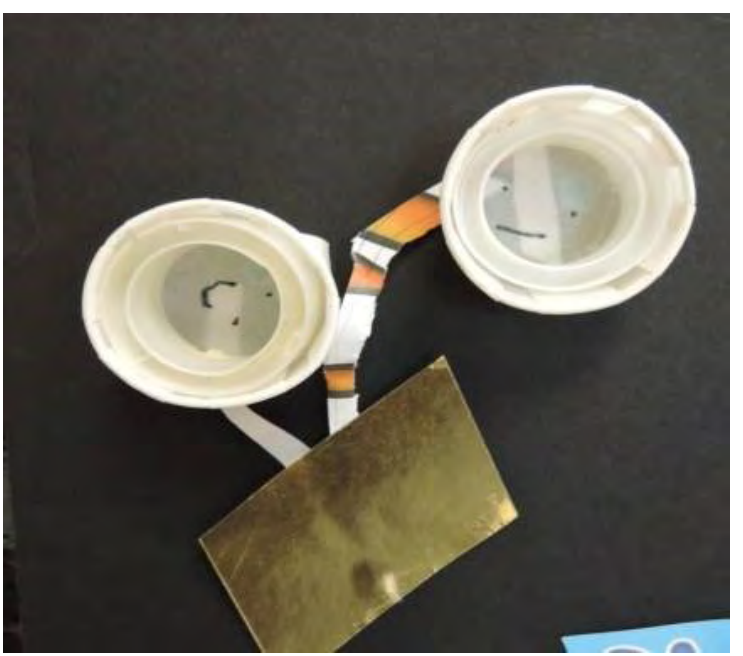

Figure 6. The double-headed serpent. "I forgot to put the tail." wondered if other children would like to try making one. We provided buttons, rings, small cups, ribbons, and variety of paper, including one with a reptile print. We brought some artworks of the double-headed serpent by Indigenous artists as a reference. This sparked the children's imagination and creativity, and they made different styles of the double-headed serpent. There seemed to be some confusion in the children's understanding of how many heads and eyes to make for the serpent.

Does it need two eyes for each head or one eye for each head? One child made two eyes on each head, but each eye turned into a face and ended up having four heads. Another child made one eye for each head. The children had a discussion on how many eyes they should make for the serpent when I pointed out, "Emma's serpent has only one eye on each head, just like one of the artists who made the serpent. Why do you think he did that?" 
"Because there was a fire, and one serpent got one eye burned and another serpent got one eye burned."

"Because the artist cannot draw on the other side. He just drew this side."

"One is facing here and one is facing there."

Later on, I learned from the Musqueam student another legend of a double-headed serpent whose two heads did not agree with each other. In this story, the eye on each head that was facing the other head was blinded so that they would not attack each other, and therefore the double-headed serpent had only two eyes altogether. Sto:lo writer Lee Maracle shares a similar image of a double-headed serpent in her novel Celia's Song (2014). She writes, "The two heads argue and as the day wears on the argument heats up until both heads are shouting and twisting to emphasize their points of view ... When two heads from the same body go to war, no one wins" (p. 23). I realized the question of how many eyes the serpent should have was not a simple math question, and I needed further research to guide children to understand the depth of the story and the significance of the double-headed serpent in Musqueam and other Coast Salish cultures.

While the children were engaged in the process of making a double-headed serpent collage, I had an opportunity to learn a little more about the doubleheaded serpent from the Musqueam Elder who had shared the story with me. I contacted him because I felt uneasy about the children's reactions of fear and worries whether the serpent was real or not. I asked: Is it appropriate to be scared of the double-headed serpent? Is it a sacred figure in Musqueam history and culture? Through the answers from the Elder, I learned:

- Musqueam people believe the serpent is very real. You cannot always see it, but you can feel by changes in the temperature and atmosphere.

- The double-headed serpent is powerful and sacred. It protects Musqueam. It is good if you need protection, but if you trouble it needlessly, it is bad.

- It is "illegal for Musqueam people to know fear."

I am learning slowly about Musqueam people and their culture through the exploration of stories, and I have started to see them as a strong nation with a tradition of warriors. Modern-day warriors are "still dedicated to protecting Musqueam culture and territory" through "such causes as language revival, land title and access to fishing" (Musqueam Indian Band, 2006, p. 19). Did the Elder share the story of the double-headed serpent with me to represent the Musqueam people's resiliency and strength through the image of reviving river grass? Is it this resiliency of warriors that keeps the Musqueam Nation strong in the history of colonialism in Canada?

I wondered what the children would think of the perspectives of the Musqueam Elder. I decided to share them by bringing back the conversation of "being scared." I retold the serpent story once again and revisited the children's first impression of the double-headed serpent as scary. After three

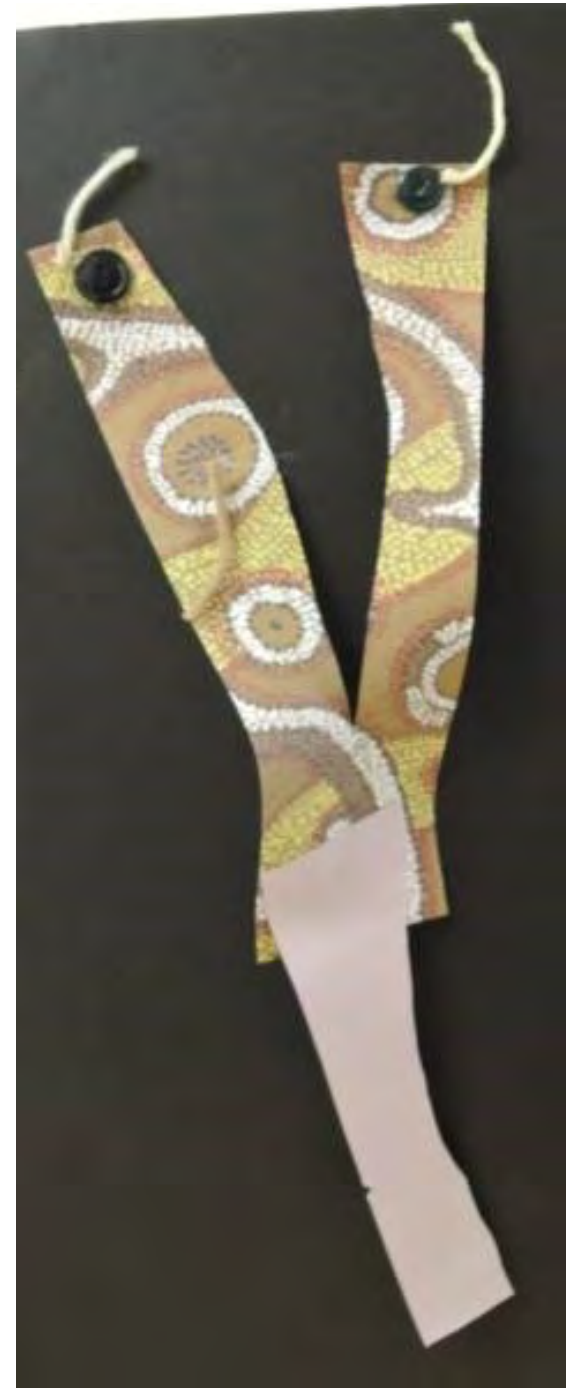

Figure 7. The double-headed serpent with tongues. 
weeks of exploration, even when I told them that "my Musqueam friend" said that the serpent was real, many children remained calm and some claimed, "I am not scared of it anymore." There were only a few who admitted, "It's scary because it's a snake. I am scared of snakes."

We also discussed the perspective from the Musqueam Elder that the serpent was strong and therefore could protect them, and they thought, "That's nice!” The other Musqueam value, that they were not supposed to be scared of anything, was also shared. How could this be possible? The children related their experiences to this question:

“I am not scared because I am brave."

"I have a special rock. If I had bad dreams, it makes me have good dreams. If I dreamed about the twoheaded serpent, it would just poop on dirt."

"I have my special stuffy Emily to cuddle with."

"I am brave because I have a sword and shield."

"I have a strong whip to make me strong."

"I am not scared because I have Mommy."

The children seemed to understand that everybody could feel scared, but they also had their own strategies to cope with fear. In their perspective, weapons seemed to be something that they could count on for their sense of security.

\section{Reflection on the double-headed serpent exploration}

When we started to explore the story of the double-headed serpent, the children were scared and worried whether the serpent was real or not. As they explored the story further, they became more familiar with the serpent. They thought about what the serpent ate (e.g., pears) and what it did (e.g., bonked on the head, “Ouch!”), which reflected their own life experiences. It seems that they tried to cope with fear toward the double-headed serpent, the unknown monster, by making it something more familiar and humorous. As the discussion on fear deepened, some children started to express their bravery and others shared their strategies to face fear. They seemed to value bravery that adults often demonstrate in front of children. The children talked about special things to help them cope with fear, such as a special rock, sword and shield, and Mommy. While they have their own strategies to be brave and strong, it seems that the children became more familiar with the double-headed serpent through repeated storytelling, drawing, and making a serpent collage over the three-week period of exploration.

I was given an opportunity to share the children's exploration of the Musqueam story with a group of Indigenous ECE students. Reflecting on the children's fear of the double-headed serpent, one student shared a poem by Chief Dan George (n.d.) from Tsleil-Waututh Nation.

If you talk to the animals they will talk with you

and you will know each other.

If you do not talk to them you will not know them, and what you do not know you will fear.

What one fears one destroys.

The poem seems to answer my wondering: Was it the unfamiliarity of the serpent that the children were actually scared of? As they listened to the story many times and mulled over the serpent's significance, have they developed 
a relationship with the serpent?

This simple wondering made me also reflect on my own fear and hesitation that I have been experiencing since we embarked on the exploration of Indigenous cultures in our preschool. The Truth and Reconciliation Commission of Canada (2015a) urges us to establish and maintain

a mutually respectful relationship between Aboriginal and non-Aboriginal peoples in this country. In order for that to happen, there has to be awareness of the past, acknowledgement of the harm that has been inflicted, atonement for the causes, and action to change behaviour. (p. 6)

Do we, the educators, also fear the unfamiliar, such as Indigenous cultures or the uncertainty of the Truth and Reconciliation process, the path that many of us are still searching for? Should we teach young children about the brutal past of colonization as a start? What is the role of an early childhood educator in order to support children along with ourselves to establish and maintain "a mutually respectful relationship" with Indigenous people? The history of colonization and Canada's residential school systems that have left a deep scar in Indigenous communities will be taught in later years as the children grow into the current school curriculum. To understand the devastation of the history, they will need to be personally connected to and appreciative of Indigenous cultures. How, then, could an educator foster a deep connection and appreciation in children? I was initially hesitant to start the exploration of Indigenous cultures and was unsure where to start, but by developing the curriculum together with the children through their wonderings and interests, I have been learning and moving forward to figure out how an early childhood educator can respond to the calls to action toward truth and reconciliation. I realize that the journey has fostered my own understanding and appreciation of Indigenous cultures and history beyond my initial fear of the unknown. Is this the fear that sets barriers between different cultures, races, or peoples in the world? Has cultural assimilation come from this fear of not knowing each other? Have many conflicts in human history arisen from this fear that is generated in people when they encounter the unknown? We, as early childhood educators, are called to action.

\section{On the last day}

The last day of our preschool term fell on June 21st, National Indigenous Peoples day, and the Elder from the Musqueam Nation that I had made a connection with invited all the children of Marpole Preschool and their families to their public celebration in their community. We made the event as our last field trip and brought as many family members as we could. Together we viewed Musqueam artworks such as house posts, welcome figures, woven blankets, and spindle whorls. Each family enjoyed the food that the Musqueam community provided, and games and crafts for the children. Some were surprised to see a man wearing a traditional Salish cedar hat, and exclaimed, "It's Chief. It's real." Some children were excited to see a real bentwood box like the one in which Sky Chief hid the sun in the Raven story, and the Musqueam race canoe on display that had come up in another Indigenous story that they had learned. Through the visit to the Musqueam event, the children and their families made a connection with the local Musqueam community and culture. They were glad that they joined the event because they "didn't know where the current Musqueam community was" otherwise. Some shared, "It was nice to know Musqueam people were so friendly and welcoming." Although these comments came from their innocence and I resonate with them, I realize they indicate the barriers that exist between non-Indigenous and Indigenous peoples: we and the other. Along with innocence, there is ignorance, and these comments show that ongoing reconciliation practices are required. Without opportunities to respectfully engage with Indigenous peoples, non-Indigenous people could remain ignorant of contemporary, local Indigenous communities. Along with the preschool exploration of a Musqueam traditional story and community visit, the children, their families, and the teachers took their very first step in the journey toward reconciliation. I believe the presence of our preschool 
community at the event also showed Musqueam people our sincere engagement with their culture and community and an action toward reconciliation to establish respectful relationships.

In the evening after our visit to the Musqueam community, Gabi and I continued our exploration of Indigenous cultures by attending the meet-the-author talk by Lee Maracle at Burnaby Public Library. She shared many stories and ideas, and the one that struck me was when she was asked how Canadians could help Indigenous peoples. Her answer was simple: "What we need is friendship, relationships, not help" (2018, n.p.). "Friendship and relationships" are what the children and the educators at Marpole Preschool have been developing for seven months, and it is our response to the following call:

Together, Canadians must do more than just talk about reconciliation; we must learn how to practise reconciliation in our everyday lives-within ourselves and our families, and in our communities, governments, places of worship, schools, and workplaces. To do so constructively, Canadians must remain committed to the ongoing work of establishing and maintaining respectful relationships. (Truth and Reconciliation Commission of Canada, 2015b, p. 11)

The Indigenous stories and artworks and the people we have come to know during the exploration supported the children, their families, and the educators to develop an authentic appreciation of their cultures. I personally grew, from being uncertain and fearful, to feeling more committed and hopeful in this journey of reconciliation. 


\section{References}

Archibald, J. (2008). Indigenous storywork: Education the heart, mind, body, and spirit. Vancouver: UBC Press.

Avery, J., Callaghan, K., \& Wien, C. A. (2016). Documenting children's meaning: Engaging in design and creativity with children and families-Inspired by the Reggio Emilia experience. Worcester, MA: Davis.

Bear, C., \& Huff, T. (2016). The honour drum: Sharing the beauty of Canada's Indigenous people with children, families, and classrooms. Lagoon City, ON: Castle Quay Books.

Beck, L. M. (1989). Heroes and heroines in Tlingit-Haida legend. Bothell, WA: Alaska Northwest Books.

Bisson, J., \& Derman-Sparks, L. (2016). Holidays and anti-bias education: Being thoughtful and creative. Child Care Exchange, September/ October. Retrieved from http://www.antibiasleadersece.com/wp-content/uploads/2016/09/Holidays-and-ABE-Bisson-DermanSparks.pdf

Cadwell, L. (1997). Bringing Reggio Emilia Home: An innovative approach to early childhood education. New York, NY: Teachers College Press.

Cameron, A. (1991). Raven goes berrypicking. Madeira Park, BC: Harbour Publishing.

Croes, D., Point, S., \& Wyatt, G. (2014). Susan Point: Works on paper. Vancouver, BC: Figure 1 Publishing.

Curtis, D., \& Carter, M. (2017). Learning together with young children: A curriculum framework for reflective teachers ( $2^{\text {nd }}$ ed.). St. Paul, MN: Redleaf Press.

Edwards, C., Gandini, L., \& Forman, G. (Eds.). (2012). The hundred languages of children: The Reggio Emilia experience in transformation. ( $3^{\text {rd }}$ ed.). Santa Barbara, CA: ABC-CLIO, LLC.

First Nations Education Steering Committee. (2015). First Peoples principles of learning. Retrieved from http://www.fnesc.ca/wp/wpcontent/uploads/2015/09/PUB-LFP-POSTER-Principles-of-Learning-First-Peoples-poster-11x17.pdf

Fraser, S. (2012). Authentic childhood: Experiencing Reggio Emilia in the classroom (3 ${ }^{\text {rd }}$ ed.). Toronto, ON: Nelson Education.

George, D. (n.d.). Talk to animals. Retrieved from https://www.poemhunter.com/poem/talk-to-animals/

Grant, L. (2013). Let's take a walk: Wo men chu qu zou zou la! Vancouver, BC: Musqueam Indian Band.

Harvey McCue \& Associates. (2010). The learning circle: classroom activities on First Nations in Canada. Retrieved from https://www. rcaanc-cirnac.gc.ca/eng/1316530132377/1535460393645

Kients, C. (2012). Raven tales: How raven stole the sun. Markham, ON: Scholastic.

MacNevin, M., \& Berman, R. (2017). The Black baby doll doesn't fit the disconnect between early childhood diversity policy, early childhood educator practice, and children's play. Early Child Development and Care, 187(5-6), 827-839. https://doi.org/10.108 0/03004430.2016.1223065

Malaguzzi, L. (2012). No way. The hundred is there. In C. Edwards, L. Gandini, \& G Forman (Eds.), The one hundred languages of children: The Reggio Emilia experience in transformation (3rd ed.; pp. 2-3). Santa Barbara, CA: ABC-CLIO, LLC.

Maracle, L. (2014). Celia's song. Toronto, ON: Cormorant Books.

McDermott, G. (2001). Raven: A trickster tale from the Pacific northwest. Boston, MA: HMH Books for Young Readers.

Meuse-Dallien, T. (2003). The sharing circle: Stories about First Nations culture. Halifax, NS: Nimbus.

Musqueam Indian Band. (2006). Musqueam: A living culture. Victoria, BC: Copper Moon.

Pape, J-G., \& Dodds, K. (n.d.). This land: A companion resource for early childhood educators to accompany five short films. Retrieved from https://drawingwisdom.ca/thisland 
Pelo, A. (2007). The language of art: Inquiry-based studio practices in early childhood settings. St. Paul, MN: Redleaf Press.

Raven Tales Productions. (2005). Raven tales episode 1: How Raven stole the sun [videorecording]. Bowen Island, BC: Author.

Suttles, W. P. (2004). Musqueam reference grammar. Vancouver: UBC Press.

Truth and Reconciliation Commission of Canada. (2015a). Honouring the truth, reconciling for the future: Summary of the final report of the Truth and Reconciliation Commission of Canada. Retrieved from http://www.trc.ca/assets/pdf/Honouring_the_Truth_ Reconciling_for_the_Future_July_23_2015.pdf

Truth and Reconciliation Commission of Canada. (2015b). Truth and Reconciliation Commission of Canada: Calls to action. Retrieved from http://trc.ca/assets/pdf/Calls_to_Action_English2.pdf

Westcoast Child Care Resource Centre. (n.d.). How raven stole the sun [information sheet]. Vancouver, BC: Author.

Williams, M. (2001). How Raven stole the sun. New York, NY: Abbeville Press. 